\title{
A Novel Portable, Economical Pump to Inject Embalming Fluid to Preserve Cadavers
}

\author{
Muthuvel Vijayan Kanagasabapathy' ${ }^{1}$, Ezhilarasan Sathurusangaravel ${ }^{2}$
}

1,2 Department of Anatomy, Government Theni Medical College, Theni, Tamilnadu, India.

\section{ABSTRACT}

\section{BACKGROUND}

Embalming is the process of treating a dead human / animal body with a chemical to protect the body from microbial spoilage and to renovate the physical appearance. Usually, it involves using formalin-based solutions. Although there are many embalming devices, most of them are heavy to lift, expensive and electrically operated. These types of electrically operated cadaveric injectors are widely used for embalming as it provides complete fixation (up to the distal parts of the limbs), and helps to save time. This study focuses on comparing a cost-effective, portable, ecofriendly embalming equipment which can run without electrical power with conventional technique.

\section{METHODS}

The comparative study of trials in checking the efficiency of the device were carried out in the Department of Anatomy, Government Theni Medical College, Theni. About 60 cadavers were received. Thirty (30) of them had been embalmed using this pump, the remaining half (30) were preserved by conventional method of embalming (i.e., electrical cadaveric injector). Embalming kit includes scalpel blade, surgical gloves, toothed- and blunt-forceps, scissors and modified fertilizer spraying pump, cannula, and pressure gauge. Arterial embalming was performed through femoral artery (femoral triangle).

\section{RESULTS}

We developed a cost-effective, portable, eco-friendly embalming equipment which does not require power and tested its efficiency in preserving about 30 cadavers. We observed that the novel method was $96 \%$ efficient.

\section{CONCLUSIONS}

The pump is highly effective in preserving the body and anyone with minimal training could use it.

\section{KEY WORDS}

Embalming, Pump, Formalin, Fixative, Cadaver Preservation, Single Point Injection Technique, Femoral Artery
Corresponding Author: Dr. Ezhilarasan Sathurusangaravel, Professor, Department of Anatomy, Government Theni Medical College, Theni - 625512, Tamilnadu, India.

E-mail: prof.drezhil@gmail.com

DOI: $10.14260 / j e m d s / 2021 / 291$

How to Cite This Article:

Kanagasabapathy VM, Sathurusangaravel E. A novel portable, economical pump to inject embalming fluid to preserve cadavers. J Evolution Med Dent Sci 2021;10(19):1377-1381, $10.14260 /$ jemds/2021/291 DOI:

Submission 24-09-2020,

Peer Review 09-03-2021,

Acceptance 16-03-2021,

Published 10-05-2021.

Copyright (C) 2021 Muthuvel Vijayan Kanagasabapathy et al. This is an open access article distributed under Creative Commons Attribution License [Attribution 4.0 International (CC BY 4.0)] 


\section{BACKGROUND}

Embalming is the process of treating the dead human body with a chemical to protect from microbial spoilage, decomposition and restoring an acceptable physical appearance. This provides sufficient time for transport of the body and help to display the deceased intact at the funeral ceremony. In this modern era, in addition to routine dissection / scientific purposes, embalming has become an artwork of guidance for funeral observation. Nowadays, embalming has evolved into a restorative and mortuary cosmetic art. It helps to restore the facial tissues and to renovate the discolorations of the deceased. Usually, it entails the injection of formalin (fixative) based solution into the arterial tree. ${ }^{1}$

Embalming has a very widespread large cultural history. The origin of embalming was over 5000 years early ( $400 \mathrm{BC}$ ). Egyptian method of preservation was said to be mummification. Egyptians believed that it presents energy to the soul after death and it would return to the preserved body. It comprised of numerous steps such as removal of brain and viscera, the immersion of the body in natron salt (20 - 70 days), dehydration, and wrapping with cloth. In another method of mummification (Xaxos), Euphorbia plant extract was introduced through the abdominal wall or into the throat. Body muscles were well preserved, hard, dry without flexibility. In Babylon, Persia, and Syria, people preserved dead bodies by placing them in containers of honey or wax. ${ }^{2}$ In the olden days of Ogoni, Nigeria, people used huge quantities of alcohol, potash, African basil (herb), and kernel oil. ${ }^{3}$ There are natural and unnatural techniques of embalming. In natural methods, it consists of mummification, preservation in cold condition; unnatural methods are routine technique of embalming, refrigeration, and plastination. It was also related with immersions / injection with alcohol.4

Before the use of formalin as a fixative, arsenic-based solutions have been utilised. Leonardo da Vinci described a method involving the use of embalming fluid mixture of turpentine, camphor, vermilion, wine, rosin, sodium nitrate, potassium nitrate and oil of lavender. Frederick Ruysch, 1665 - 1717) developed the first successful arterial embalming. Alexander Butlerov and Wilhelm von Hofmann were renowned for their invention of formaldehyde. During war period, Thomas Holmes (1817 - 1900) embalmed more than 4000 bodies and patented the chemicals used for it; hence, he was viewed to be the father of modern embalming. In 1832 and 1871 , the anatomy acts have been amended into law, declaring that cadavers should be embalmed and then dissected to train college students of medicine, dentistry, physiotherapy, scientific laboratory sciences, and for anatomical research. In the anatomy laboratory, human cadavers have been considered to be a precious academic tool for medical students. ${ }^{2}$ In medical education, anatomists and students make use of the cadavers for dissection and demonstration of specimens.

From 1920 onward, various changes in embalming chemicals, ingredients, and concentrations were introduced to limit the formalin exposure, tissue hardening / darkening. ${ }^{1}$ Isopropyl alcohol with more quantity of salt was used for embalming; with this method, the microscopic anatomy of the tissues was preserved for a long period. ${ }^{5}$ Paraffin impregnation was established in $1925 .{ }^{1}$ Thiel's embalming fluid comprises of ammonium nitrate, boric acid, potassium nitrate, ethylene glycol, p-chlorocresol solution, chlorocresol, ethylene glycol, formaldehyde and sodium sulphide; it was followed and encouraged for cadaver workshops as it retains the colour of the tissues and flexibility of the joints. Due to flexibility of the muscles, Thiel's technique was more beneficial to surgical, anaesthesia trainees for learning skills and training in laparoscopy, plastic surgery, tracheal intubation, natural orifices endoscopic surgery, ultrasound regional anaesthesia 6

We earlier reported wax-based embedding method as one of the economic technique of cadaver preservation; which maintains the morphology, additionally presents dry and formalin free specimen; this facilitates student access to cadaver and protects them from health hazards associated with formalin. ${ }^{7}$ Plastination, anatomical specimen preservation technique was carried out with the help of pressured impregnation with polymers such as silicone, epoxy, or polyester resins, which on drying yield permanent, lightweight, and reasonable specimens. ${ }^{8}$

There are many cadaver embalming devices in use such as electrical injector (with compressor motor), gravity-based perfusion tank (positioned " $3 \mathrm{~m}$ " high from the ground), mechanical pump, bulb syringe and hand pump. Hand pump similar to a large hypodermic syringe was attached to a bottle apparatus. It was used to create either pressure for injection or vacuum for aspiration. Bulb syringe hand-held and handoperated device comprises of a rubber bulb with hoses fixed at the end. There is one-way valve in the device allowing the pump to work. One hose was placed into a container of embalming solution. Arterial solution flows into the bulb when the device is relaxed. Once the bulb is full, squeezing the bulb forces the arterial solution into the delivery hose and into the body. It is important to remember that the solution actually passes through the bulb syringe. Pressures are unknown and it does require the use of one hand. Main drawback in handling the bulb syringe was that, building pressure within the body makes the bulb syringe tougher to squeeze. Each of them has their merits and demerits. Electrical cadaver injector requires power supply, and it is laborious to transport. In gravity perfusion tank, handling and maintenance is difficult.

Hence, this study focuses on developing a cost-effective, portable, eco-friendly embalming equipment without electrical power requirement and checks its effectiveness in preserving the cadaver.

\section{METHODS}

The comparative study of embalming is a routine procedure in anatomy laboratory. The efficiency of the device was evaluated in the Department of Anatomy, Government Theni Medical College, Theni and compared with conventional method.

There are two classes of bodies received in the department - one for dissection purpose (52) and the other was received through family (8) for funeral embalming. About sixty cadavers had been obtained in the duration from Jan 2013 to Dec 2019. Thirty (30) of them have been embalmed using this pump, the remaining half (30) were preserved by conventional method of embalming (i.e., electrical cadaveric injector)

The artery preferred in the study was femoral artery in the femoral triangle. Embalming fluid was prepared as given in 
Table $1 .^{9}$ and arterial embalming was carried out via single point injection technique.

\begin{tabular}{|c|c|c|c|}
\hline Sl. No. & Role of the Chemical & Chemical Used & Quantity Used \\
\hline \multirow{2}{*}{1} & \multirow{2}{*}{ Preservative } & Formalin & $10 \%$ \\
\hline & & Methanol & $55 \%$ \\
\hline 2 & Buffer & Sodium borate & $1.5 \%$ \\
\hline 3 & Anticoagulant & Sodium citrate & $1.5 \%$ \\
\hline 4 & Wetting agent & Glycerine & $15 \%$ \\
\hline 5 & Germicide & Phenol & $5 \%$ \\
\hline 6 & Vehicle & Water & $15 \%$ \\
\hline 7 & Fungicide & Thymol & Few crystals \\
\hline 8 & Dye & $1 \%$ Eosin & $0.5 \%$ \\
\hline 9 & Perfume soluble & Soluble winter green & $0.1 \%$ \\
\hline
\end{tabular}

Embalming kit includes scalpel blade, surgical gloves, toothed and blunt forceps, scissors and modified fertilizer spraying pump, cannula, and pressure gauge.

\section{Conventional Method}

In a well-ventilated, illuminated dissection hall, cadavers were placed in anatomical position. Using electrical cadaveric injector, the embalming fluid was pumped through the femoral artery (femoral triangle).

\section{Functioning of the Device}

In this work, the embalming pump was installed over the flat, steady (ground) surface. Before using the device, the inlet tube was well immersed into the embalming fluid and we assured that the connections (inlet tube, outlet tube) of the device were proper to avoid leakage (Figure 2). Extremities and neck were positioned in anatomical position for future dissection, as embalming produces rigidity in joints and muscles.

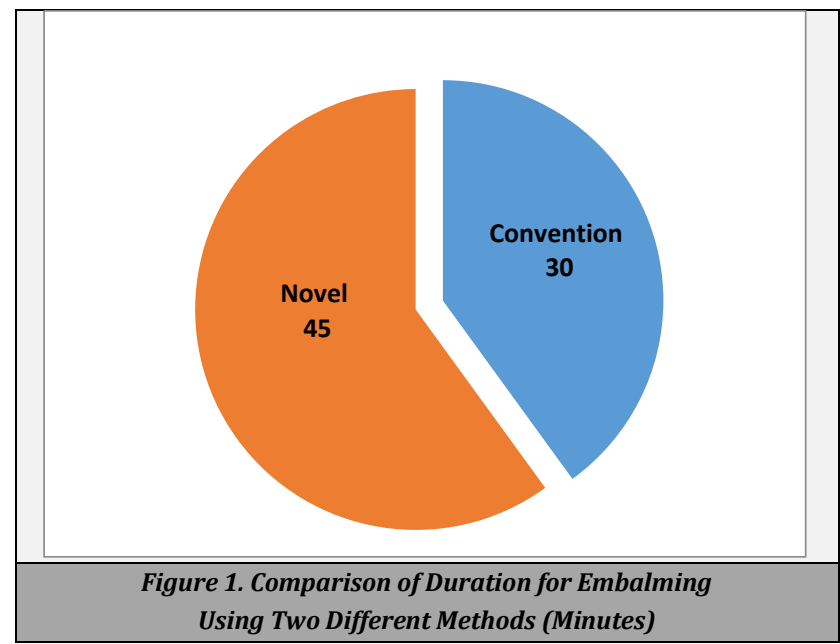

In the initial phase of the study, propagation of cannula was challenging in few ( $\mathrm{N}=4)$ well-built bodies, because femoral arterial plane was found lying deep. At this condition, common carotid artery (anterior triangle) was used for embalming as common carotid artery has a large diameter. Anterior vertical incision was made on the anterior triangle of the neck. Dissection was made through platysma, superficial fat and fascia. After raising the internal jugular vein, the vein was pushed laterally. In deep and medial plane, common carotid artery was raised.

Other cadavers $(\mathrm{N}=56)$, the femoral artery was exposed via making a vertical incision $5-10 \mathrm{~cm}$ below the mid inguinal area (femoral triangle). Dissection was carried out through the superficial fat and tissues. After locating the medial margin of the sartorius muscle, femoral artery was located and dissected free from vein. ${ }^{1}$ A longitudinal incision was made on the artery enabling the insertion of the cannula for embalming.

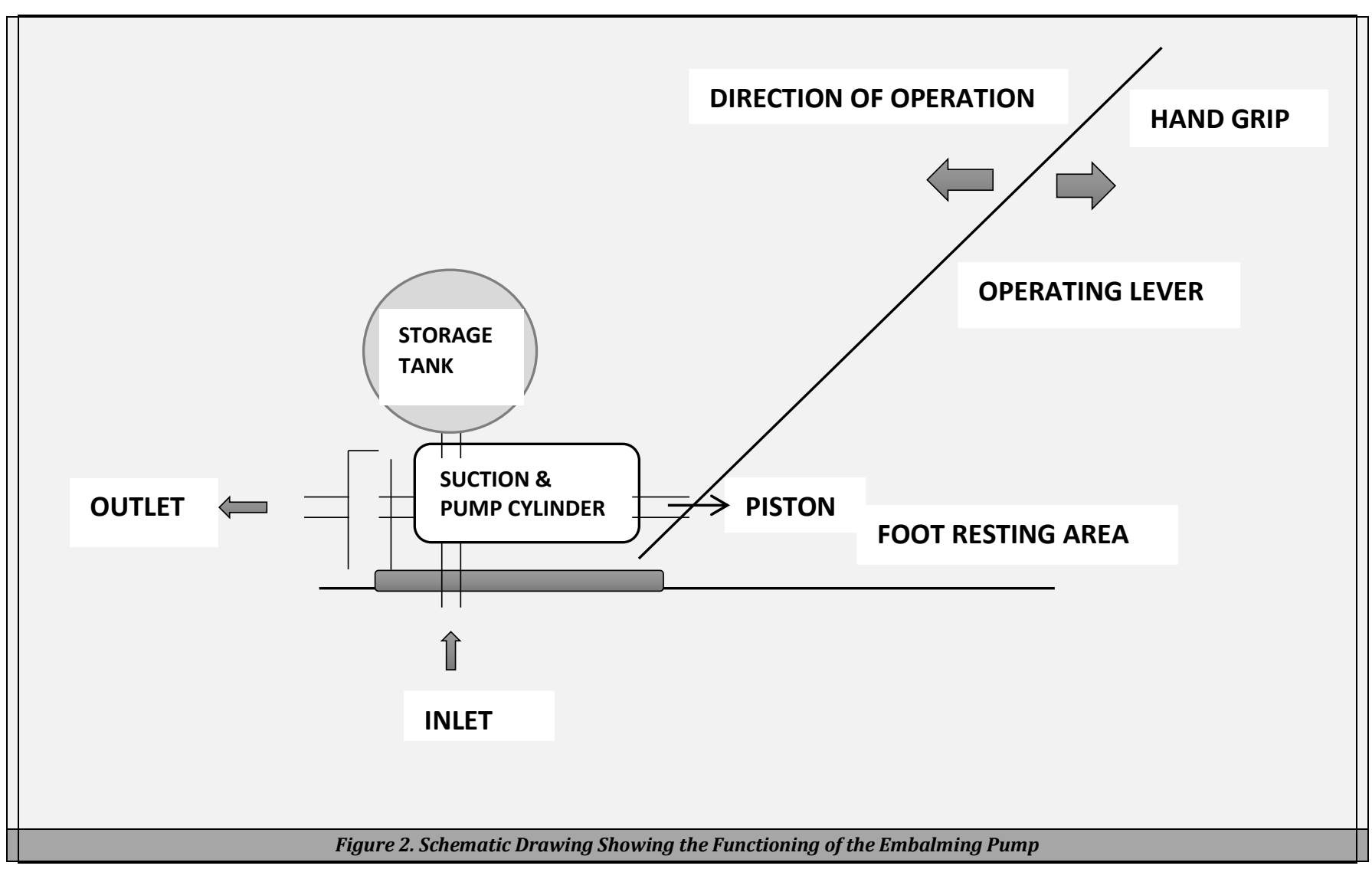


The pump was operated with the help of a lever. Keeping the cannula valve (Figure 2) closed, the lever was pushed front and pulled back for generation of negative pressure which draws the embalming fluid from the source (container with embalming fluid) to the tank and necessary pressure which is required to inject the fluid from the tank into the artery. In the next step, carefully the cannula was inserted into the artery. Subsequently, the cannula valve is opened; the fluid stored in the tank was allowed to flow into the artery. During the embalming procedure, as a safety measure, goggles were used. Resistance in pumping indicates pressure overload.

At this stage, continuous pumping should be avoided. By the time, embalming fluid ooze out via the oral and nasal opening, the operation of the instrument was stopped. After shutting the cannula valve, gently withdraw the cannula from the artery. Then, ligate the artery firmly and close the incision with the aid of suture.

\section{Quantity of Embalming Fluid Injected}

Numerous factors determine the strength and amount of arterial fluid which include age, weight, moisture content of body, time between preparation and disposal of body that have been refrigerated. Average amount of fluid injected was around 10 litres. $^{9}$

\section{Statistical Analysis}

Descriptive statistics was used to measure the findings in this research. The data was collected and statistically analysed. StatCalc software was used.

\section{RESULTS}

In this study, total number of 60 cadavers were embalmed; while majority were males $82 \%$ (49), females were $18 \%$ (11). Average age group of the deceased was 53 years, ranging from 31 - 78. Among the total of 60 cadavers, $2.4 \%$ (4) of the study was embalmed by using common carotid artery.

\begin{tabular}{|lcl|}
\hline Method of Embalming & Efficacy \% & Cost Effectiveness \\
Conventional & $99.25 \%$ & $4.7 \%$ \\
Novel & $96.4 \%$ & $62 \%$ \\
\hline \multicolumn{3}{|r|}{ Table 2. Comparison of Efficacy and } \\
& Cost Effectiveness between the Two Methods \\
\hline
\end{tabular}

In 60 cadavers embalmed, both methods had been unsuccessful to embalm the cadavers in $3 \%(2 / 60)$ of the study due to vascular associated pathological conditions. Routinely, it requires 30 minutes to accomplish a successful injection of embalming fluid by conventional method (i.e., electrical cadaveric injector). In the initial phase of usage of the device, improper immersion of the inlet tube into the embalming fluid paved way to air bubble entry into the body that minimised the quality of embalming. By proper immersion of the inlet tube into the fluid and careful observation of the fluid level, significant improvement in results was attained. With this pump, we observed uniform perfusion of fluid throughout the body and there is no need to inject at different parts of the body. Prior to the injection, pressure generated had been measured with the help of pressure gauge, and was found to be in the range of 12 - $15 \mathrm{lbs}$ max. Over the period of 6 years, 60 cadavers had been embalmed. Departmental faculties found out that this device was safe and easy to operate. Some $(\mathrm{N}=5)$ of the embalmed cadavers have been maintained and monitored over a duration of two years to verify the effectiveness of this embalming method. Our study confirmed that the cadavers had been preserved from microbial spoilage, safe to handle, and maintained its morphology.

\section{DISCUSSION}

Formalin is a colourless, toxic preservative chemical with irritating pungent odour. It was stored and handled with care in the preparation room. Excess concentrations of formalin may produce dehydration or hardening of tissues. Formaldehyde vapours and fumes may cause irritation to mucous membranes of respiratory tract and eyes. Hence, adequate air flow and cross- ventilation is essential in preparation room and embalming room. ${ }^{1}$ In this study, adequate ventilation, lighting and temperature were maintained. During embalming, exhaust ventilation system was kept functional. Embalming chemicals interacted with body proteins and made them inert firm material which was not easily spoiled / decomposed. Formalin mainly denatures or coagulates the protein Refurbishing the outlook of the facial tissues, removing vascular discolorations could be achieved by injection of embalming chemicals. ${ }^{1}$

After completion of the embalming procedure, proper disinfection of the body and environment were carried out. In the post embalming monitoring phase, there was no colour, odour, desquamation (skin slip) in the embalmed bodies. The cadavers were accessed twice a day. Two days later, for checking the quality of embalming, medial side of the palm was dissected and firm texture in muscle was noticed. Later, the cadavers were immersed in formalin tanks $(10 \%)$. After a week, depending upon the requirement, the bodies were utilised for dissection purposes.

Electrical cadaveric injector is too heavy to lift, whereas this pump weighs only $9 \mathrm{~kg}$. This pump doesn't emit smoke, noise and does not require fuel (petrol / diesel), electrical power resources; this instrument is eco-friendly, hassle free, easily portable and it was suitable and reliable for all seasons and any field purposes.

Periodical inspection (i.e., once / twice a year) and maintenance of the device is advisable. In this study, successful embalming was confirmed by looking at the cadaver texture, darkening, tightening of distal parts of the body. ${ }^{1}$

\section{CONCLUSIONS}

The pump is effective for embalming the human cadavers and anyone with minimal training could operate the device. We observed that the results were on par with electrical cadaveric injector. In this study, we have described an alternative and reliable device for embalming. Being portable and economical, it could also be used for remote and rural villages. During power failure and electrical inaccessibility. This method may be employed in other medical institutes. Further studies are 
needed to explore its application in preservation of biological and veterinary specimens.

Data sharing statement provided by the authors is available with the full text of this article at jemds.com.

Financial or other competing interests: None.

Disclosure forms provided by the authors are available with the full text of this article at jemds.com.

Authors are thankful to Dr. S.P.Banumathi Professor \& Director of Institute of Anatomy (Retd) Madurai Medical College, Madurai, Dr. T.Thirunavukarasu Dean, for their constant support and encouragement during the course of the work and writing the paper.

\section{REFERENCES}

[1] Mayer RG. Embalming: history, theory and practice. New York: McGraw-Hill 2012.

[2] Blessing AA, Olubunmi EE, Abidemi AO. Human embalming techniques: a review. American Journal of Biomedical Sciences 2018;10(2):82-95. doi:10.5099/aj180200082

[3] Udoaka AI, Oghenemavwe L, Ebenezer T. Ancient embalming techniques amongst the Ogoni tribe in
Southern Nigeria. Journal of Experimental and Clinical Anatomy 2009;8(2).

[4] Brenner E. Human body preservation-old and new techniques. J Anat 2014;224(3):316-44. doi: 10.1111/joa.12160

[5] Coleman R, Kogan I. An improved low-formaldehyde embalming fluid to preserve cadavers for anatomy teaching. J Anat 1998;192(3):443-6.

[6] Benkhadra M, Bouchot A, Gerard J, et al. Flexibility of Thiel's embalmed cadavers: the explanation is probably in the muscles. Surg Radiol Anat 2011;33(4):365-8. DOI 10.1007/s00276-010-0703-8

[7] Ezhilarasan S, Vijayan KM, Jeyanthi M. Wax embedding technique-innovative and cost effective method of preservation of human cadaveric specimens. Indian Journal of Clinical Anatomy and Physiology 2016;3(4):423-6.

[8] Dhanwate AD, Gaikwad MD. Plastination- a boon to medical teaching \& research. International Journal of Science and Research 2015;4(5):1550-53.

[9] Ajmani ML. Embalming: principles and legal aspects. New Delhi: Jaypee 2009. 